\title{
ROS-mediated downregulation of MYPT1 in smooth muscle cells: a potential mechanism for the aberrant contractility in atherosclerosis
}

\author{
Jung-Chien Cheng ${ }^{1}$, Hui-Pin Cheng ${ }^{1,2}$, I-Ching Tsai ${ }^{1,3}$ and Meei Jyh Jiang ${ }^{1,2,3,4}$
}

Reactive oxygen species (ROS) mediates the aberrant contractility in hypertension. Abnormal contractility occurs in atherosclerotic vessels but changes in proteins that regulate contractility remain poorly understood. Myosin phosphatase (MP) activity, which regulates smooth muscle relaxation, is regulated by the phosphorylation of its regulatory subunit, MP targeting subunit 1 (MYPT1). In the present study, we examined the roles of ROS in MP subunit expression both in cultured human aortic smooth muscle cells (HASMCs) and during atherosclerosis progression in apolipoprotein E-knockout (apoE-KO) mice. Furthermore, the effect of decreased MYPT1 on actin cytoskeleton and cell migration activity was assessed in HASMCs. Short hairpin RNA-mediated knockdown of MYPT1 increased stress fibers and attenuated platelet-derived growth factor-induced cell migration in HASMCs. Superoxide anion-inducing agent LY83583 downregulated MYPT1 mRNA and protein levels, but did not affect the phosphorylation of MYPT1 and catalytic subunit of MP, PP1 $\delta$. The LY83583-induced decrease in MYPT1 was abolished by co-treating with superoxide dismutase or by inhibiting NADPH oxidase with diphenyleneiodonium. Treatment of peroxynitrite, but not hydrogen peroxide $\left(\mathrm{H}_{2} \mathrm{O}_{2}\right)$, downregulated MYPT1 protein expression and induced MYPT1 phosphorylation without affecting mRNA levels. Co-treatment with a proteasome inhibitor, MG-132, eliminated peroxynitrite-induced MYPT1 downregulation. In apoE-KO mice, MYPT1 protein, but not mRNA, levels were markedly decreased in 16-week- and 24-week-old mice. Oral estrogen treatment, which was previously shown to decrease aortic ROS levels, upregulated aortic MYPT1 expression. Moreover, reduction in MYPT1 expression correlated with increased aortic sensitivity toward vasoconstrictors. These results suggested that during atherosclerosis progression oxidative stress mediates the downregulation of MYPT1, which may inhibit smooth muscle cell migration and contribute to the aberrant contractility.

Laboratory Investigation (2013) 93, 422-433; doi:10.1038/labinvest.2013.40; published online 18 February 2013

KEYWORDS: atherosclerosis; contractility; myosin phosphatase; reactive oxygen species; smooth muscle

At the molecular level, phosphorylation of the $20-\mathrm{kDa}$ myosin light chains $\left(\mathrm{MLC}_{20}\right)$ is a key determinant for smooth muscle contraction. $\mathrm{MLC}_{20}$ phosphorylation levels are determined by the activity ratio between myosin light chain kinase (MLCK) and myosin phosphatase (MP). ${ }^{1}$ Although MLCK activation depends on cytoplasmic calcium concentration, MP activity is subject to modulation by various signaling molecules. ${ }^{2}$

$\mathrm{MP}$ is a heterotrimer comprised of a $37-$ to $38-\mathrm{kDa}$ catalytic subunit $(\mathrm{PP} 1 \delta)$, a 110 - to $130-\mathrm{kDa}$ regulatory subunit (MP targeting subunit 1 ; MYPT1), and a $20-\mathrm{kDa}$ subunit of unknown function. The phosphorylation of MYPT1 by protein kinases is a major regulatory mechanism for MP that results in either the inhibition or enhancement of MP activity. ${ }^{3}$ Small GTPase RhoA and its effecter, Rho-kinase, inhibit MP activity through MYPT1 phosphorylation, ${ }^{4}$ and mediate calcium sensitization of smooth muscle contraction. ${ }^{5}$ In contrast, relaxation of smooth muscle results from nitric oxide (NO)-stimulated activation of MP, which is mediated by cGMP and cGMP-dependent protein kinase (PKG). ${ }^{6,7}$ Several MYPT1 isoforms identified to date are products of a gene with alternative splicing of a central

\footnotetext{
'Department of Cell Biology and Anatomy, College of Medicine, National Cheng Kung University, Tainan, Taiwan; ${ }^{2}$ Institute of Basic Medical Science, College of Medicine, National Cheng Kung University, Tainan, Taiwan; ${ }^{3}$ Medical Device Innovation Center, National Cheng Kung University, Tainan, Taiwan and ${ }^{4}$ Cardiovascular Research Center, National Cheng Kung University, Tainan, Taiwan

Correspondence: Dr MJ Jiang, PhD, Department of Cell Biology and Anatomy, College of Medicine, National Cheng Kung University, 1 Ta-Hsueh Road, Tainan 70101, Taiwan.
}

E-mail: mjiang@mail.ncku.edu.tw

Received 2 July 2012; revised 15 December 2012; accepted 24 January 2013 
and a $3^{\prime}$ exons. No distinct functions are known for the central insert isoforms. ${ }^{8}$ The exclusion of the 31-bp $3^{\prime}$ exon shifts the reading frame and results in a C-terminal leucine zipper (LZ) motif, while exon inclusion encodes a MYPT1 lacking the LZ motif. ${ }^{9}$ In vitro and in vivo evidence showed that the LZ motif present in the C-terminal of MYPT1 is required for the activation of MP by type I PKG. ${ }^{10-12}$ The sensitivity of smooth muscle to cGMP/PKG-mediated relaxation is proportional to the expression ratio of $\mathrm{LZ}^{+}$/ $\mathrm{LZ}^{-}$MYPT1. ${ }^{10-12}$

In smooth muscle cells, the relationship between MP activity and the phosphorylation of MYPT1 has been extensively studied. ${ }^{13}$ However, changes in MYPT1 abundance have only been reported by a few studies. ${ }^{14,15}$ The contractile response induced by a phosphatase inhibitor, okadaic acid, in the rat uterus differs significantly between early and late pregnancy; this response coincides with changes in PP $1 \delta$ and MYPT1, but not MLCK, mRNA levels. ${ }^{15}$ Hypoxia-induced reduction in contractility and $\mathrm{MLC}_{20}$ phosphorylation of rat aortic smooth muscle results from elevation in MYPT1 expression and MP activity. ${ }^{14}$ It remains unclear whether the expression levels of MP subunits are altered in atherosclerosis. Furthermore, the roles of MYPT1 in the migration of vascular smooth muscle cells have not been addressed.

Atherosclerosis is the underlying mechanism for various cardiovascular diseases, including coronary heart disease and stroke. ${ }^{16}$ Anomalies in vasoconstriction and vasodilatation are among the multifaceted disorders that manifest in atherosclerosis. ${ }^{17}$ Reactive oxygen species (ROS), such as superoxide $\left(\mathrm{O}_{2}{ }^{-}\right)$, hydroxyl radical $(\cdot \mathrm{OH})$, and hydrogen peroxide $\left(\mathrm{H}_{2} \mathrm{O}_{2}\right)$, have gained recognition as essential factors in the pathogenesis of atherosclerosis. ${ }^{18}$ In the vasculature, NADPH oxidases are critical factors for the aberrant ROS production in various disorders. ${ }^{19}$ Cumulative evidence indicated that oxidative stress from increased production or insufficient removal of ROS aids the progression of atherosclerosis. ${ }^{18,19}$ Our previous study demonstrated that long-term oral estrogen treatment reduces ROS levels and atherosclerosis progression in apolipoprotein E-knockout (apoE-KO) mice, which suggests atheroprotective effects via anti-oxidative actions. ${ }^{20}$

The bioavailability of endothelium-derived NO is negatively modulated by the presence of superoxide, as these two molecules react with high affinity to produce peroxynitrite $\left(\mathrm{ONOO}^{-}\right)$. This highly reactive oxidant is involved in endothelial dysfunction and cardiovascular diseases. ${ }^{21,22}$ ROSmediated oxidation has been shown to increase the sensitivity of proteins undergoing degradation, which is involved in the pathogenesis of many human diseases including atherosclerosis. $^{23,24}$ Moreover, recent studies showed that NO inhibits vascular smooth muscle cell proliferation and prevents neointimal hyperplasia by regulating proteasomemediated protein degradation..$^{25,26}$ These studies indicate that ROS-mediated protein degradation may contribute to the progression of atherosclerosis.
In the current study, we examined the role of MYPT1 in cell motility in cultured human aortic smooth muscle cells (HASMCs) and tested the hypothesis that ROS-regulated MP expression contributes to the abnormal contractility in atherosclerosis. Our results provide the first evidence that MYPT1 participates in vascular smooth muscle cell migration. Furthermore, ROS-induced downregulation of MYPT1 expression through transcriptional regulation and protein degradation potentially contributes to abnormal contractility in atherosclerosis.

\section{MATERIALS AND METHODS \\ Antibodies and Reagents}

The polyclonal anti-MYPT1 antibody was obtained from Covance (Berkeley, CA) and Millipore (Temecula, CA). The polyclonal anti-phosphoMYPT1 ${ }^{\text {Thr696 }}$, anti phosphoMYPT $1^{\text {Thr850 }}$, and anti-PP1 $\delta$ antibody were obtained from Upstate (Lake Placid, NY). Horseradish peroxidase-conjugated goat anti-rabbit IgG and horse anti-mouse IgG were obtained from Chemicon (Temecula, CA) and Vector Laboratories (Burlingame, CA), respectively. The blocking buffer SuperBlock was obtained from Thermo (Rockford, USA). The antibody diluent was obtained from Dako (Carpinteria, CA, USA). The monoclonal anti- $\alpha$-tubulin antibody, diphenyleneiodonium chloride (DPI), $\mathrm{H}_{2} \mathrm{O}_{2}$, phenylephrine, sodium nitroprusside (SNP) and polyethyleneglycol-conjugated superoxide dismutase (PEG-SOD) were obtained from Sigma (St. Louis, MO). LY83583 and MG-132 were purchased from Calbiochem (La Jolla, CA). Peroxynitrite and U46619 were purchased from Cayman Chemical (Ann Arbor, MI). Platelet-derived growth factorBB (PDGF-BB) was obtained from R \& D Systems (Lake Placid, NY). All other chemicals were reagent grade.

\section{Cell Culture and Treatment}

HASMCs were purchased from Cascade Biologics (Portland, OR) and were grown in medium 231 supplemented with smooth muscle growth supplement (Cascade Biologics). Cultured cells were maintained at $37^{\circ} \mathrm{C}$ in a humidified atmosphere of $5 \% \mathrm{CO}_{2}$ in air. HASMCs were grown to $80 \%$ confluence and serum-starved in medium 231 containing $0.2 \%$ FBS for $24 \mathrm{~h}$ to induce quiescence. The cells were treated with LY83583, $\mathrm{H}_{2} \mathrm{O}_{2}$, or peroxynitrite for $24 \mathrm{~h}$, followed by cell lysis or RNA extraction.

\section{Animals and Tissue Preparation}

Female apoE-KO mice and the control C57/BL6 (B6) mice were obtained from the Animal Center of National Cheng Kung University. The mice were housed in an environmentally controlled room with free access to food and water. Six-week-old apoE-KO mice were fed a cholesterolcontaining diet $(0.15 \%$ cholesterol, TestDiet, Richmond, IN, USA) to facilitate atherosclerotic lesion formation. B6 and apoE-KO mice between 8 and 24 weeks of age were used in this study. The investigation conforms to the Guide for the 
Care and Use of Laboratory Animals published by the US National Institutes of Health, and was conducted in accordance with the institutional guidelines. Thoracic aortas were removed from animals anesthetized with sodium pentobarbital $(100 \mathrm{mg} / \mathrm{kg}$, i.p. $)$ and cleaned of perivascular tissues in oxygenated $\left(95 \% \mathrm{O}_{2}-5 \% \mathrm{CO}_{2}\right)$ physiological saline solution (PSS, $\mathrm{pH}$ 7.4) with the following composition (in $\mathrm{mM}): 120 \mathrm{NaCl}, 5.9 \mathrm{KCl}, 25 \mathrm{NaHCO}_{3}, 1.2 \mathrm{NaH}_{2} \mathrm{PO}_{4}, 11.5$ dextrose, $1.2 \mathrm{MgCl}_{2}$ and $2.5 \mathrm{CaCl}_{2}$.

\section{Short Hairpin RNA Transfection}

Plasmids (pLKO.1) encoding short hairpin RNA (shRNA) for MYPT1 (shMYPT1) and luciferase (shLuc) were purchased from the National RNAi Core Facility (Academia Sinica, Taipei, Taiwan). HEK293 cells were transfected with pLKO.1shMYPT1, pCMV- $\Delta$ R8.91 and pMD.G for $24 \mathrm{~h}$, and viral particles were collected from conditioned medium to test for gene knockdown efficiency in HASMCs. HASMCs were infected with lentivirus containing MYPT1 shRNA (shMYPT1) or control vector (shLuc) for $12 \mathrm{~h}$ and incubated with fresh medium for $48 \mathrm{~h}$. Three shMYPT1 (shMYPT1-3, shMYPT14, and shMYPT1-5) plasmids were tested and two (shMYPT1-3 and shMYPT1-5) were used in the later experiments. The sequences targeted by the shRNA are: $5^{\prime}$-GCA GCT CGA AAG GAA GAA GAA-3' (shMYPT1-3), 5'-CCA GAA CGT ATG ATG AGA CTT- $3^{\prime}$ (shMYPT1-4), and $5^{\prime}$-TTG CGA ACA AGT AGT TCA TAT-3' (shMYPT1-5).

\section{Immunofluorescence Staining}

HASMCs were fixed with $4 \%$ buffered paraformaldehyde and then permeabilized with $0.1 \%$ Triton X-100 in PBS. The cells were incubated with SuperBlock containing 1\% goat serum and subsequently with anti-MYPT1 (1:100 in DAKO diluent) and FITC-phalloidin $(1: 2000)$ at $37^{\circ} \mathrm{C}$. The nuclei were counterstained with Hoechst 33342. Fluorescence intensity was analyzed with Image Pro-Plus 6.0.

\section{Transwell Migration Assay}

Cell culture inserts (pore size $8 \mu \mathrm{m}$; Millipore, Billerica, MA) were precoated with type I collagen and seeded with cells in serum-free medium. Medium with $1 \mathrm{nM}$ PDGF-BB was added to the lower chamber and served as a chemotactic agent. After $5 \mathrm{~h}$ of incubation, the non-migrating cells were wiped from the upper side of the membrane. The cells that penetrated the membrane were fixed with cold methanol. The cell nuclei were stained with $10 \%$ Giemsa and counted under microscope.

\section{Western Blot Analysis}

Frozen aortas were placed in dry ice-acetone slurry containing $10 \%$ trichloroacetic acid (TCA) and $10 \mathrm{mM}$ dithiothreitol (DTT) to thaw. The aortas were washed three times with acetone containing $10 \mathrm{mM}$ DTT to remove TCA. Thoracic aortas were homogenized in a buffer containing $20 \mathrm{mM}$ MOPS, $2 \%$ SDS, 10\% glycerol, and protease inhibitor cocktail ( $1 \mu \mathrm{M}$ aprotinin, $1 \mu \mathrm{M}$ leupeptin, and $1 \mathrm{mM}$ PMSF). HASMCs were lysed in buffer $(20 \mathrm{mM}$ Tris pH 7.4, $2 \mathrm{mM}$ EGTA, $2 \mathrm{mM} \mathrm{Na}_{2} \mathrm{VO}_{3}, 2 \mathrm{mM} \mathrm{Na}_{4} \mathrm{P}_{2} \mathrm{O}_{7}, 2 \%$ Triton X-100, $2 \%$ SDS, and protease inhibitor cocktail). The protein concentration was analyzed by BCA protein assay kit (Pierce). Samples with equal amount of protein were separated by SDS-polyacrylamide gel electrophoresis and transferred to nitrocellulose membranes. Following blocking with Trisbuffered saline containing 3\% non-fat dry milk, the membranes were subsequently incubated with anti-pMYPT1 ${ }^{\text {Thr696 }}$ (1:1000), anti-pMYPT1 ${ }^{\text {Thr850 }}$ (1:1000), anti-MYPT1 (1:3000) or anti-PP1 $\delta(1: 1000)$, and with HRP-conjugated secondary antibody (1:5000). The immunoreactive bands were detected with enhanced chemiluminescence kit. The membrane was stripped and reprobed with anti- $\alpha$-tubulin (1:5000) as the loading control.

\section{Semi-Quantitative RT-PCR}

The aortas were homogenized, and HASMCs were lysed with $1 \mathrm{ml}$ TRIzol reagent (Invitrogen) to extract total RNA. The RNA concentration was determined by spectrophotometric measurement at $260 \mathrm{~nm}$. Reverse transcription was performed with $3 \mu \mathrm{g}$ of RNA, random primers, and M-MLV reverse transcriptase. PCR was conducted with $10 \%$ RT product and primers specific for human MYPT1 (forward: 5' - TAG ATA TTG CGG AGG AGG AG-3'; reverse: $5^{\prime}$ - CAC TTT GTT GAC CAT CTC CA-3'), human PP1d (forward: $5^{\prime}$ GGG GGC CTC TCT TGT TTA TT- $3^{\prime}$; reverse: $5^{\prime}$ - CAA ATT TTC AGC GGT GCT TC-3'), human GAPDH (forward: $5^{\prime}$ TGA AGG TCG GAG TCA ACG GA-3'; reverse: $5^{\prime}$-CAT GTG GGC CAT GAG GTC CA-3'), mouse MYPT1 (forward: $5^{\prime}$ GAT TCC TTG CTG GGT CGC TC-3'; reverse: $5^{\prime}$-AGG CTC CAT TTT CAT CCT TT- $3^{\prime}$ ), mouse PP1 $\delta$ (forward: $5^{\prime}$-AAC CAT GAG TGT GCT AGC ATC A-3'; reverse: 5'-CAC CAG CAT TGT CAA ACT CGC C- $3^{\prime}$ ), and mouse GAPDH (forward: $5^{\prime}$-GTT TGT GAT GGG TGT GAA CC-3'; reverse: $5^{\prime}$ CTC TTG CTC AGT GTC CTT GC- $\left.3^{\prime}\right)$. PCR experiments $\left(94{ }^{\circ} \mathrm{C}, 40 \mathrm{~s} ; 55^{\circ} \mathrm{C}, 40 \mathrm{~s} ; 72^{\circ} \mathrm{C}, 80 \mathrm{~s}\right)$ were performed for 24 cycles for MYPT 1 and PP $1 \delta$. Twenty PCR cycles $\left(94^{\circ} \mathrm{C}, 60 \mathrm{~s}\right.$; $58^{\circ} \mathrm{C}, 60 \mathrm{~s} ; 72^{\circ} \mathrm{C}, 120 \mathrm{~s}$ ) were performed for GAPDH. The reverse transcription-PCR (RT-PCR) products were separated by gel electrophoresis on $2 \%$ agarose, stained with ethidium bromide, and visualized under a UV transilluminator.

\section{Immunohistochemistry}

Cryostat sections of aortas ( $10 \mu \mathrm{m}$ thick) were fixed with acetone $\left(-20^{\circ} \mathrm{C}\right)$ for $10 \mathrm{~min}$, permeabilized with $0.1 \%$ Triton X-100 for $5 \mathrm{~min}$, and blocked with $3 \%$ BSA in PBS. Endogenous peroxidase was blocked with $5 \mathrm{~min}$ incubation of $3 \% \mathrm{H}_{2} \mathrm{O}_{2}$. Aortic sections were subsequently incubated with anti-MYPT1 antibody (1:50 in PBS), biotinylated goat anti-rabbit IgG (1:500 in PBS-1\% BSA), and avidin-biotinperoxidase complex (Vectastain $A B C$ kit). The sections were detected by aminoethylcarbazole (Zymed AEC kit), mounted 
with Kaiser's glycerol gelatin, and photographed under a microscope. A negative control in the absence of primary antibody was performed in parallel.

\section{Isometric Tension Measurement}

Aortic rings of 20-week-old apoE-KO and B6 mice were used in this experiment. The isolated descending thoracic aortas were cleaned and cut into 2.5 -mm-wide rings. Aortic rings were held in muscle holders, placed in tissue bathes, and connected to force transducers. Following equilibration under a resting tension of $0.7 \mathrm{~g}$ at $37^{\circ} \mathrm{C}$ for $1-1.5 \mathrm{~h}$, the aortic rings were stimulated twice with $51 \mathrm{mM} \mathrm{KCl-PSS} \mathrm{to} \mathrm{stabilize}$ contraction. Isometric tension in response to $\alpha_{1}$-adrenoceptor agonist phenylephrine or thromboxane $\mathrm{A}_{2}$ analog U46619 was measured. Relaxation was measured by adding cumulative concentrations of SNP to aortic rings precontracted with phenylephrine or U46619.

\section{Statistical Analysis}

The results are presented as the mean \pm s.e.m. Statistical evaluation was conducted by $t$-test for paired data. Multiple comparisons were analyzed by one-way ANOVA, followed by Tukey's multiple comparison tests. The statistical significance was defined as $P<0.05$.

\section{RESULTS}

Knockdown of MYPT1 Increases Stress Fiber Formation and Attenuates PDGF-induced Cell Migration

During atherosclerosis progression, smooth muscle cell migration from the media to the intima is a major contributor to the formation of fibroatheroma. ${ }^{16}$ In the HeLa cells, the small-interfering RNA-mediated downregulation of MYPT1 promotes stress fiber formation and inhibits cell migration. ${ }^{27}$ Therefore, we investigated whether the downregulation of MYPT1 modifies actin organization and cell migration in HASMCs. Lentivirus-encoding MYPT1 shRNA was used to knockdown endogenous MYPT1 expression in cultured HASMCs. Western blot analysis showed that all three MYPT1 shRNAs (shMYPT1-3, shMYPT1-4, and shMYPT1-5) markedly reduced the MYPT1 levels compared with cells infected with lentivirusencoding shLuc (Figure 1a). Immunofluorescence staining showed that MYPT1 was localized in the cytoplasm and nucleus of the untreated control, as well as cells infected with lenti-shLuc, which was reported previously. ${ }^{28,29}$ MYPT1 shRNA significantly reduced MYPT1 expression in HASMCs. In addition, phalloidin staining showed that MYPT1 knockdown promoted stress fiber formation (Figure 1b). Quantification of fluorescence indicated that HASMC transfected with shMYPT1-3 and shMYPT1-5 exhibited lower cellular MYPT1 levels and higher phalloidin staining compared with the control groups (Figure 1c, $P<0.05)$. MYPT1 levels decreased significantly in both cytoplasm and nucleus with the cytoplasm exhibiting higher degree of reduction (Figure 1d). We next examined the effect of MYPT1 knockdown on HASMC migration stimulated by PDGF-BB, which is a potent chemoattractant for smooth muscle cells. ${ }^{30}$ Using transwell migration assay, PDGF-BB significantly increased HASMC migration. MYPT1 knockdown attenuated the PDGF-induced cell migration without significantly changing the basal levels (Figure 1e).

\section{Superoxide Decreases the MYPT1 mRNA and Protein Levels in HASMC}

To examine the effect of ROS on MYPT1 expression, the superoxide inducer LY83583 was used to generate oxidative stress in HASMCs. ${ }^{31}$ LY83583 treatment at $1 \mu \mathrm{M}$ and $3 \mu \mathrm{M}$ induced the superoxide production in HASMCs by 12- and 27-fold, respectively, as measured by lucigenin-derived chemiluminescence (Figure 2a). LY83583-induced superoxide production was abolished by treatment with membrane-permeable PEG-SOD or DPI (Figure 2b). DPI is an inhibitor of flavoenzymes which blocks NADPH oxidase activity. RT-PCR revealed that LY83583 treatment for $24 \mathrm{~h}$ decreased the MYPT1, but not PP1 $\delta$ mRNA expression (Figure 2c). Western blot analysis showed that the MYPT1 protein levels, but not PP1 $\delta$, were downregulated more profoundly than mRNA by LY83583 treatment in HASMCs (Figure 2d). Moreover, the LY83583-induced downregulation of MYPT1 was abolished by PEG-SOD and DPI treatment (Figure 2e).

\section{Peroxynitrite, but not $\mathrm{H}_{2} \mathrm{O}_{2}$, Decreases MYPT1 Protein Levels by Activating Proteasome-mediated Protein Degradation}

To further examine whether the metabolites of superoxide, $\mathrm{H}_{2} \mathrm{O}_{2}$ and peroxynitrite, modulate MYPT1 expression, HASMCs were treated with increasing concentrations of $\mathrm{H}_{2} \mathrm{O}_{2}$ and peroxynitrite $(100 \mu \mathrm{M}, 250 \mu \mathrm{M}$, and $500 \mu \mathrm{M})$ for $24 \mathrm{~h}$. RT-PCR and western blot analyses showed that $\mathrm{H}_{2} \mathrm{O}_{2}$ treatment did not alter the MYPT1 mRNA and protein levels (Figure 3a). Treatment with $500 \mu \mathrm{M}$ peroxynitrite for $24 \mathrm{~h}$ significantly decreased the MYPT1 protein expression. Interestingly, peroxynitrite treatment did not affect MYPT1 mRNA levels; this finding suggests that protein degradation may be involved in peroxynitrite-induced downregulation of MYPT1 protein expression (Figure $3 b$ ). To test this possibility, HASMCs were treated with peroxynitrite in the presence of a proteasome inhibitor, MG-132. As shown in Figure 3c, MG-132 treatment alone increased the MYPT1 protein expression. Furthermore, co-treatment of peroxynitrite with MG-132 reversed the peroxynitrite-induced reduction of MYPT1 protein levels. In addition, $500 \mu \mathrm{M}$ peroxynitrite treatment did not induce procaspase-3 cleavage or increase annexin V-positive cells, which indicated that peroxynitriteinduced downregulation of MYPT1 protein levels did not attribute to the cell apoptosis (Supplementary Figure 1). 

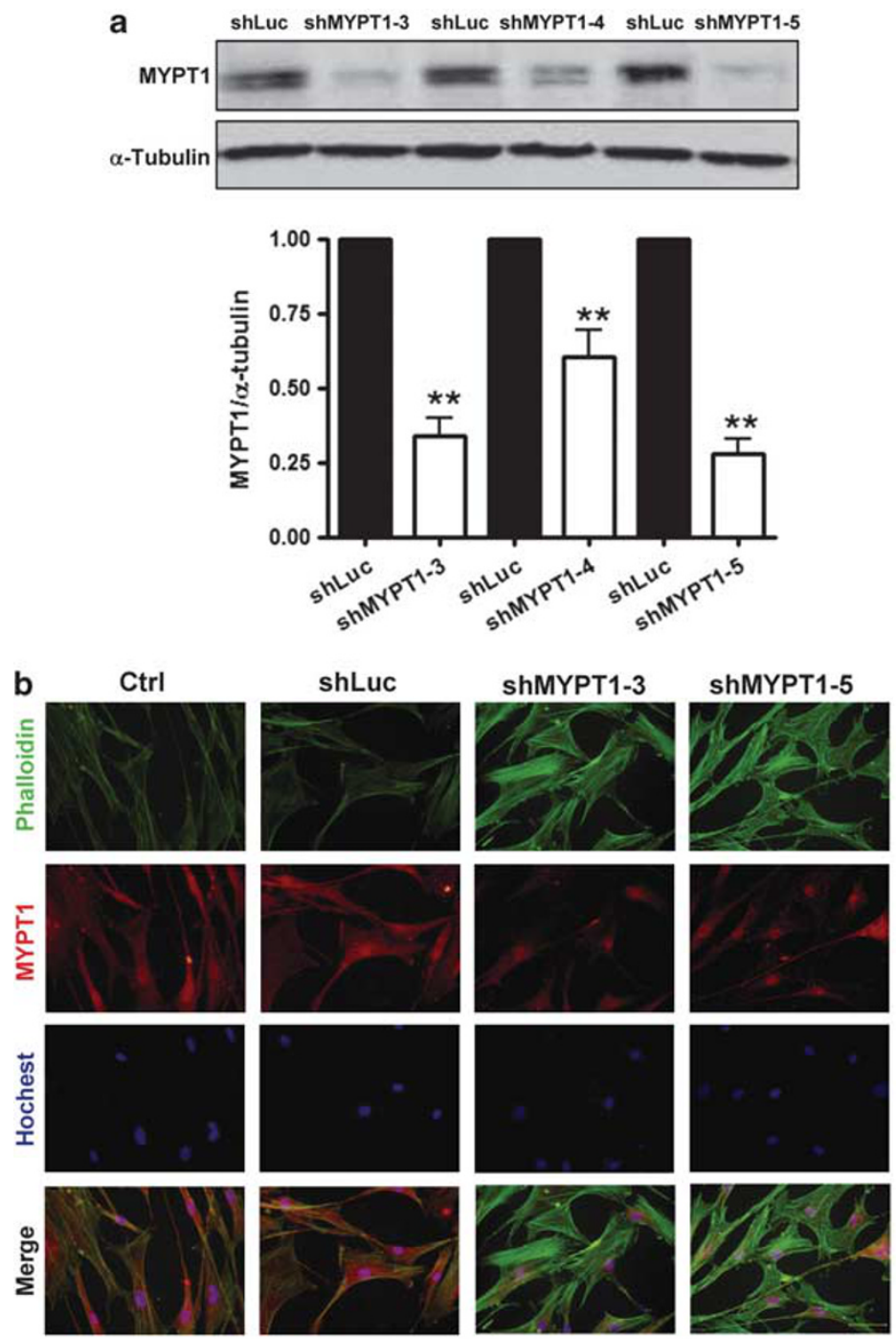

Figure 1 The effects of myosin phosphatase targeting subunit 1 (MYPT1) knockdown on actin cytoskeleton organization and cell migration in human aortic smooth muscle cells (HASMCs). (a) HASMCs were infected with lentivirus-encoding MYPT1 short hairpin RNA (shRNA; shMYPT1-3, shMYPT1-4, and shMYPT1-5) or control vector (shLuc) for $60 \mathrm{~h}$, and MYPT1 protein expression was examined by western blot analysis. (b,c, and d) HASMCs were infected with lentivirus-encoding shMYPT1-3, shMYPT1-5, or shLuc for $60 \mathrm{~h}$ and fixed with $4 \%$ buffered paraformaldehyde. MYPT1 expression was examined by immunofluorescence staining. Actin filaments were stained by FITC-phalloidin. Nuclei were counterstained with Hoechst 33342 . b Shows representative staining results; c shows the quantified MYPT1 and phalloidin fluorescence in four experimental groups with regression lines $(n=50$ cells/group); d summarizes cytoplasmic and nuclear MYPT1 immunofluorescence in four experimental groups ( $n=180 \sim 210 /$ group). (e) Uninfected HASMCs (Ctrl) and cells infected with lentivirus-encoding shMYPT1-3, shMYPT1-5, or shLuc were seeded onto transwell inserts, treated with $10^{-9} \mathrm{M}$ PDGF $(+\mathrm{P})$, and cultured for $5 \mathrm{~h}$. The migrated cells were stained with Giemsa and counted. The migration results were normalized with the untreated control (Ctrl) and expressed as mean \pm s.e.m. of three independent experiments. ${ }^{*} P<0.05,{ }^{* *} P<0.01$ compared with shLuc; ${ }^{\#} P<0.05$ compared with shLuc + P. Scale bar: $50 \mu \mathrm{m}$.

\section{Peroxynitrite, but not Superoxide or $\mathrm{H}_{2} \mathrm{O}_{2}$, Increases MYPT1 Phosphorylation}

Phosphorylation of MYPT1 has been shown to inhibit MP activity and contributes to the calcium sensitization of smooth muscle contraction. ${ }^{4,5}$ We therefore examined whether ROS treatment affects the phosphorylation of MYPT1 in HASMCs. As shown in Figure 4, treatment with LY83583 and $\mathrm{H}_{2} \mathrm{O}_{2}$ for $30 \mathrm{~min}$ or $1 \mathrm{~h}$ did not affect phosphorylation of MYPT1 at either Thr696 or Thr850. Interestingly, treatment with peroxynitrite for $1 \mathrm{~h}$ significantly increased phosphorylation levels of MYPT1 at both Thr696 and Thr850.

MYPT1 Protein, but not mRNA, Levels are Decreased in the Aorta during Atherosclerosis Progression

To examine whether MYPT1 expression varied during atherosclerosis progression, MYPT1 protein levels were investigated in the aorta by western blot analysis in apoE-KO mice that were between 8 and 24 weeks old. The MYPT1 expression decreased $58 \%$ and $75 \%$ in 16 - and 24 -week-old 

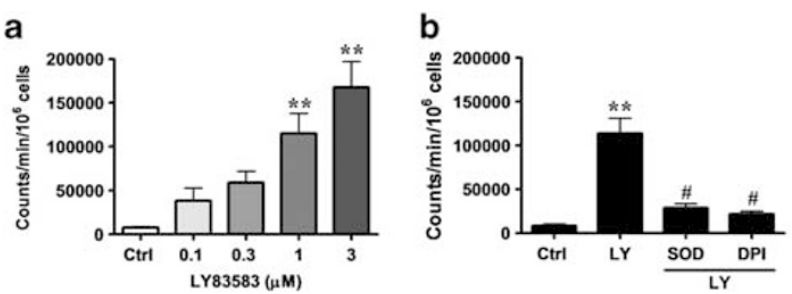

C

MYPT1
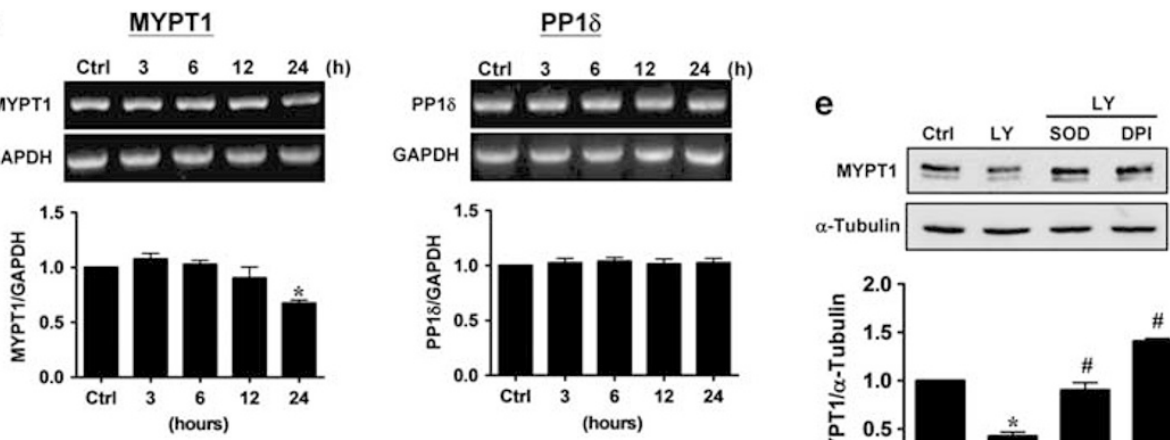

d

MYPT1
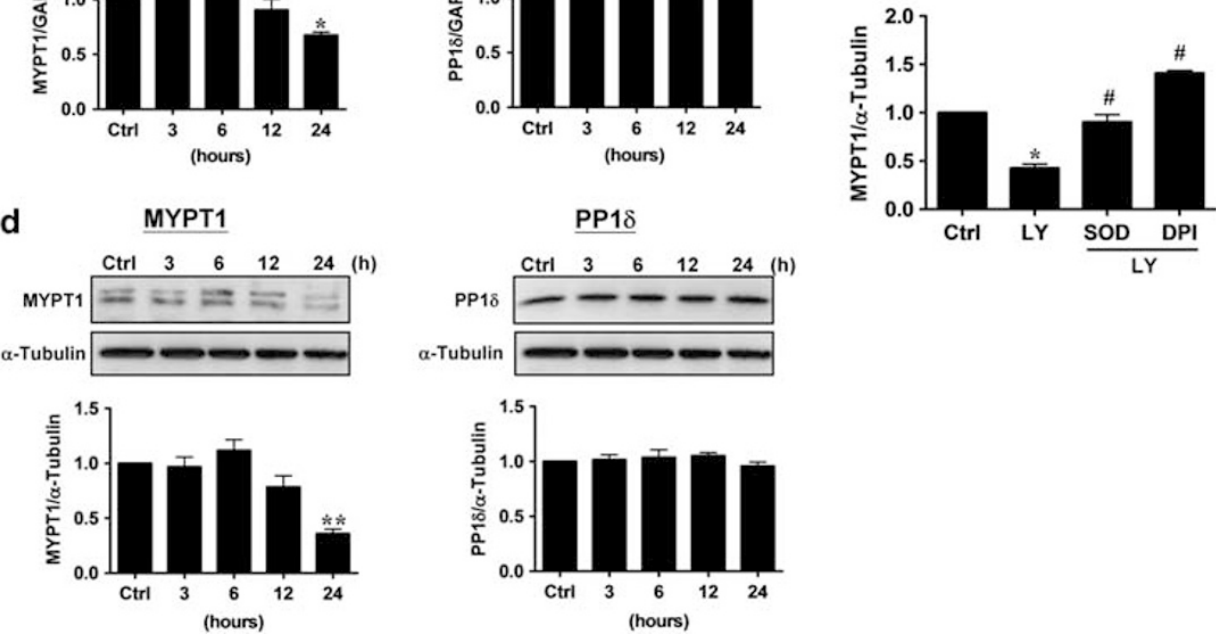

Figure 2 The effects of LY83583 on myosin phosphatase subunits, myosin phosphatase targeting subunit 1 (MYPT1) and PP1 $\delta$ expression in human aortic smooth muscle cells (HASMCs). (a) HASMCs were treated with increasing doses of LY83583 (LY, $0.1,0.31$, and $3 \mu$ M). The superoxide production was measured by lucigenin-derived chemiluminescence. (b) HASMCs were treated with the $1 \mu \mathrm{M} \mathrm{LY} 83583$ for $24 \mathrm{~h}$ in the presence or absence of $50 \mathrm{U} / \mathrm{ml}$ polyethyleneglycol-conjugated superoxide dismutase (PEG-SOD) or $5 \mu \mathrm{M}$ DPI. The superoxide production was measured by lucigenin-derived chemiluminescence. (c, d) HASMCs were serum-starved for $24 \mathrm{~h}$ and treated with $1 \mu \mathrm{M}$ LY83583 for the indicated durations. MYPT1 (left panel) and PP1 $\delta$ (right panel) mRNA levels were examined by RT-PCR (c) whereas protein levels were examined by western blot analysis (d). (e) Serum-starved HASMCs were treated with the $1 \mu \mathrm{M} \mathrm{LY} 83583$ for $24 \mathrm{~h}$ in the presence or absence of $50 \mathrm{U} / \mathrm{ml} \mathrm{PEG-SOD}$ or $5 \mu \mathrm{M}$ DPI. The MYPT1 protein levels were analyzed by western blot analysis. The results were normalized with the untreated control (Ctrl) and expressed as the mean \pm s.e.m. of three independent experiments. ${ }^{*} P<0.05,{ }^{*} P<0.01$ compared with $\mathrm{Ctrl} ;{ }^{*} P<0.01$ compared with $\mathrm{LY}$ alone.

apoE-KO mice, respectively, compared with age-matched B6 mice (Figure 5a). By contrast, PP $1 \delta$ expression did not vary significantly between apoE-KO mice and $\mathrm{B} 6$ mice in all age groups (Figure 5a). We further examined MYPT1 expression and distribution with immunohistochemistry in aortic sections from 24-week-old apoE-KO and B6 mice. Strong MYPT1 immunoreactivity was detected in the aortic media of B6 mice. In contrast, MYPT1 staining was weak in the aortic media and intima of apoE-KO mice, which is consistent with the western blot results (Figure 5b). Because the aortic MYPT1 protein levels significantly decreased along atherosclerosis progression, we examined whether aortic MYPT1 mRNA levels changed during the same period. As shown in Figure $5 c$, two RT-PCR products were detected in the aortas of apoE-KO and $\mathrm{B} 6$ mice; the molecular sizes of these products were 358 and $389 \mathrm{bp}$, corresponding to the
LZ-positive and LZ-negative RNA transcripts of MYPT1, respectively. In contrast to changes in protein levels, total MYPT1 mRNA levels did not vary significantly between apoE-KO mice and B6 mice in all age groups. Furthermore, the percentage of LZ-positive MYPT1 mRNA isoform was similar between the two groups (Figure $5 \mathrm{c}$ ).

\section{Oral Estrogen Treatment Increased Aortic MYPT1 Expression in ApoE-KO mice}

Our previous study showed that decreased oxidative stress is an important mediator for atheroprotective effects of oral estrogen treatment on apoE-KO mice. ${ }^{20}$ Therefore, we examined whether estrogen treatment also modulates aortic MYPT1 expression in 24-week-old ovariectomized apoE-KO mice. As shown in Figure 6, oral $17 \beta$-estradiol $(6 \mu \mathrm{g} /$ day $)$ treatment for 12 weeks markedly increased MYPT1 expres- 
a
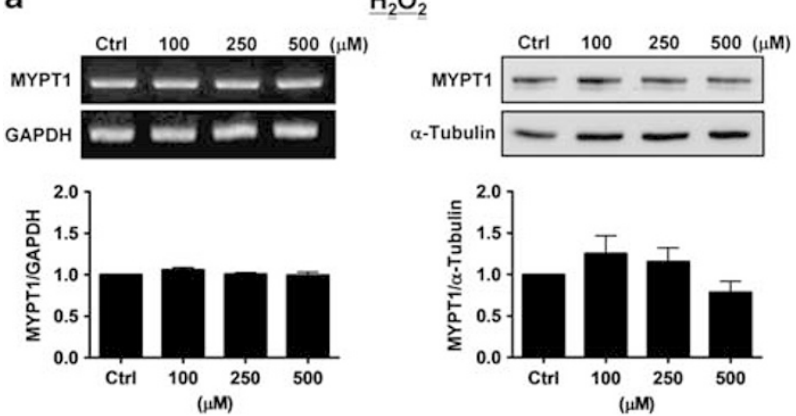

Peroxynitrite

b
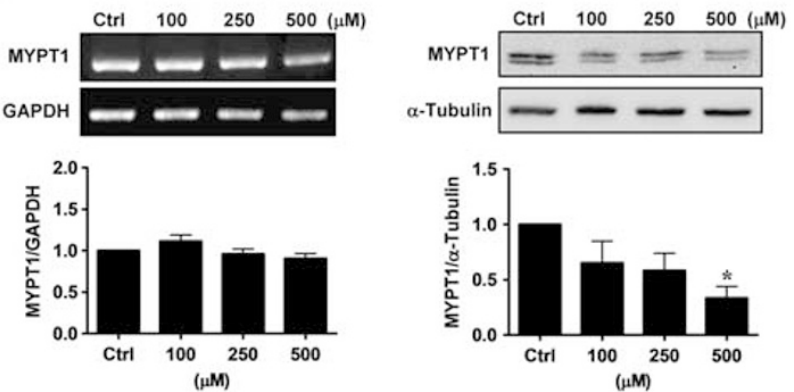

C
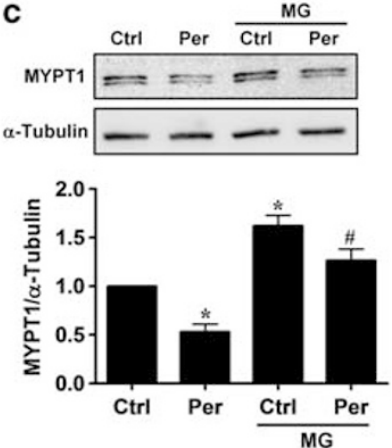

Figure 3 The effects of $\mathrm{H}_{2} \mathrm{O}_{2}$ and peroxynitrite on myosin phosphatase targeting subunit 1 (MYPT1) expression. (a, b) Human aortic smooth muscle cells (HASMCs) were serum-starved for $24 \mathrm{~h}$ and treated with increasing doses $(100 \mu \mathrm{M}, 250 \mu \mathrm{M}$, and $500 \mu \mathrm{M})$ of $\mathrm{H}_{2} \mathrm{O}_{2}(\mathbf{a})$ or peroxynitrite (b) for $24 \mathrm{~h}$. The mRNA (left panel) and protein (right panel) levels were examined by RT-PCR and western blot analyses, respectively. (c) HASMCs were serumstarved for $24 \mathrm{~h}$ and treated with $500 \mu \mathrm{M}$ peroxynitrite (Per) in the presence and absence of $1 \mu \mathrm{M}$ MG-132 for $24 \mathrm{~h}$. MYPT1 protein expression was evaluated by western blot analysis. The results were normalized with the control and expressed as the mean \pm s.e.m. of four independent experiments. ${ }^{*} P<0.05$ compared with Ctrl; ${ }^{\#} P<0.05$ compared with peroxynitrite alone.

LY83583

$\underline{\mathrm{H}}_{2} \mathrm{O}_{2}$

Peroxynitrite

$\begin{array}{lll} & \text { Ctrl } 30 \mathrm{~min} \quad 1 \mathrm{~h} \\ \text { pMYPT1 }^{\text {Thr696 }} & \\ \text { pMYPT1 }^{\text {Thr850 }} \\ \text { MYPT1 } \\ \alpha \text {-Tubulin }\end{array}$

pMYPT $1^{\text {Thr696 }}$
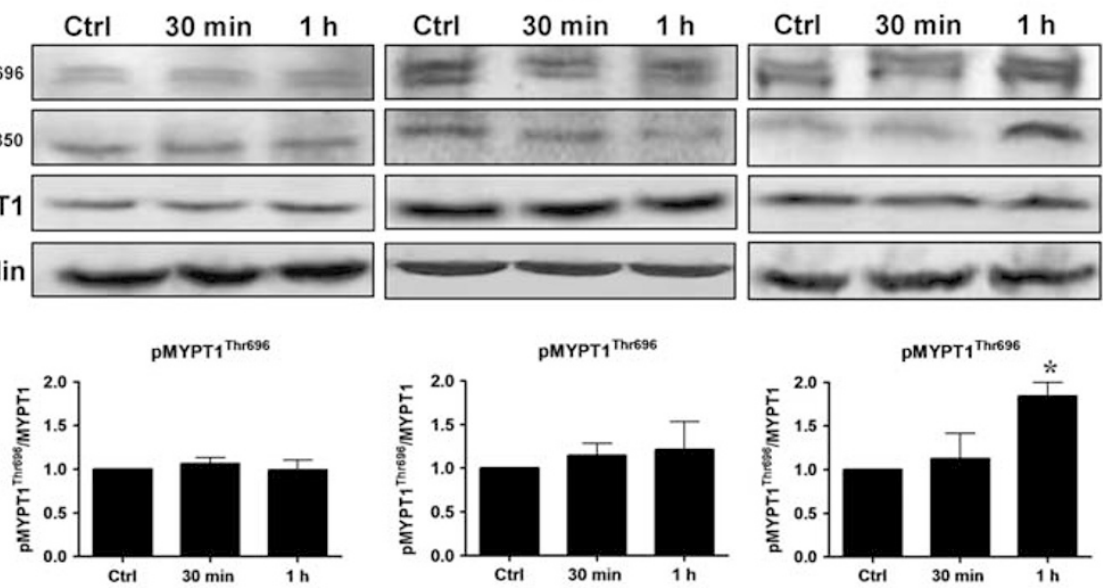

pMYPT $^{\text {Thr696 }}$
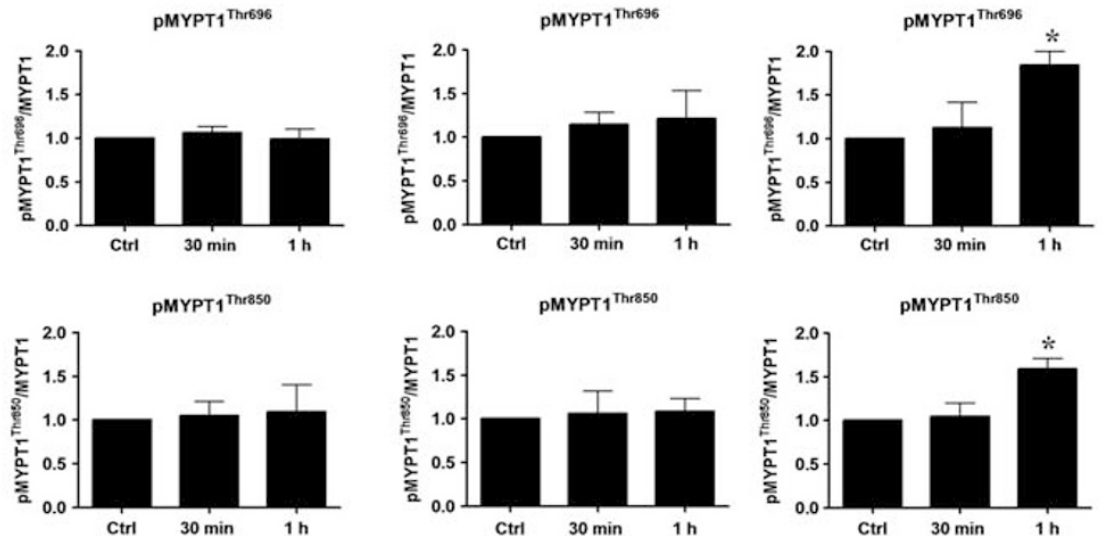

Figure 4 The effects of reactive oxygen species (ROS) on MYPT1 phosphorylation. Human aortic smooth muscle cells (HASMCs) were serum-starved for $24 \mathrm{~h}$ and treated with LY83583 $(1 \mu \mathrm{M}), \mathrm{H}_{2} \mathrm{O}_{2}(500 \mu \mathrm{M})$, or peroxynitrite $(500 \mu \mathrm{M})$ for 30 min or $1 \mathrm{~h}$. The phosphorylation levels of MYPT1 at Thr696 and Thr850 were examined by western blot analyses and normalized against total MYPT1 levels. * $P<0.05$ compared with Ctrl. 

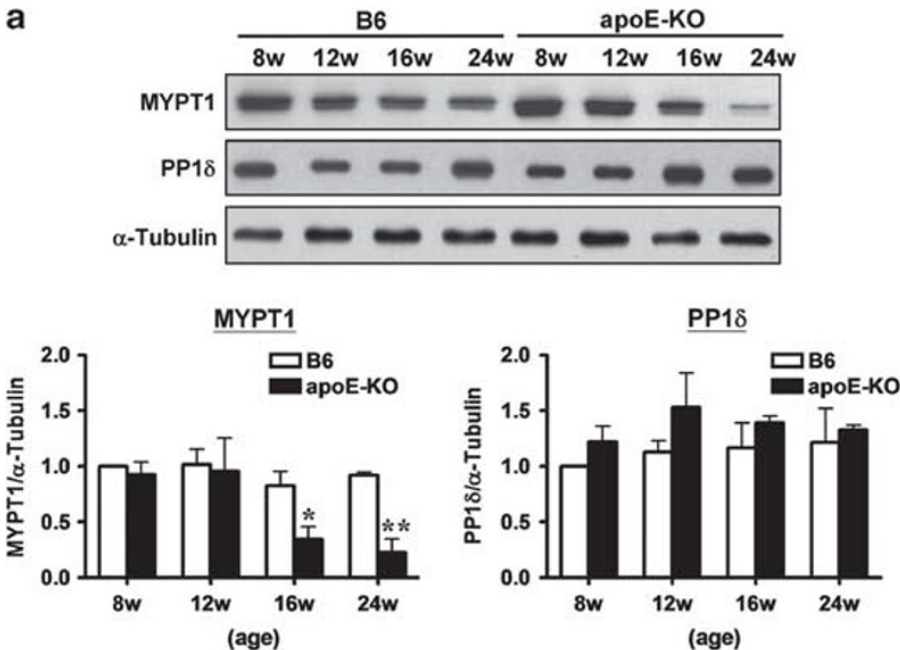

b
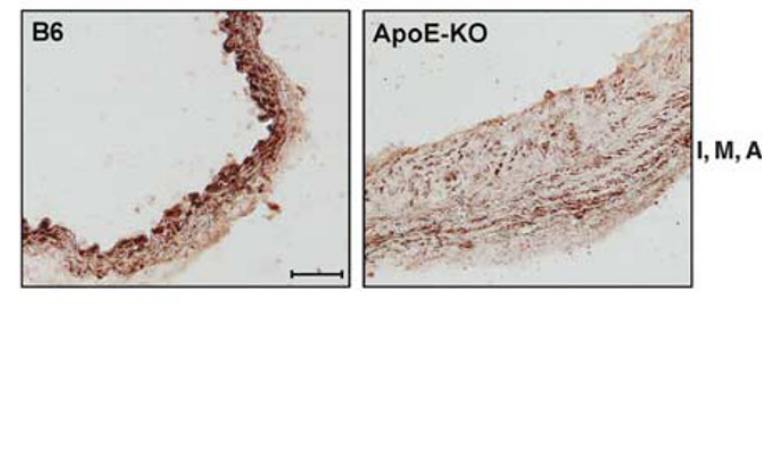
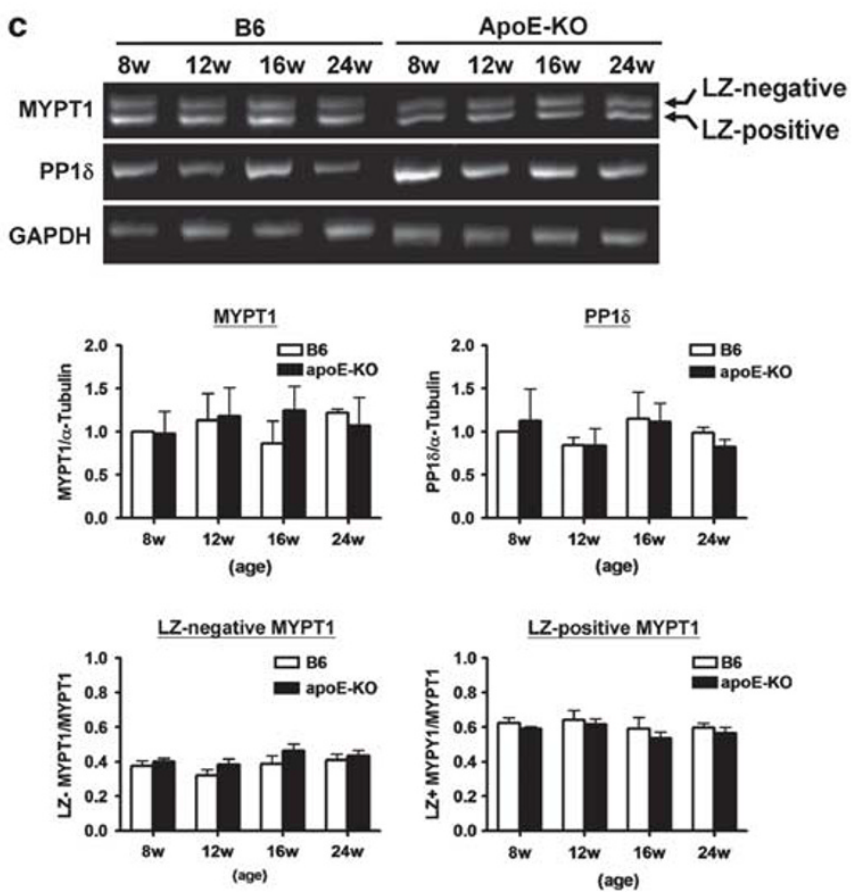

Figure 5 Aortic expression of myosin phosphatase subunits, myosin phosphatase targeting subunit 1 (MYPT1) and PP1 $\delta$, during atherosclerosis progression. (a) Tissue homogenate of thoracic aorta from 8- to 24-week-old apolipoprotein E-knockout (apoE-KO) and B6 mice was analyzed by western blot analysis with anti-MYPT1 and anti-PP1 $\delta$ antibodies using $\alpha$-tubulin as the loading control. The top panel shows representative blots of protein expression; the bottom panel shows densitometry results. (b) Cryosections of aorta from 24-week-old B6 mice (left panel) and apoE-KO mice (right panel) were stained with an anti-MYPT1 antibody. Dotted lines indicate the tunica media. I: intima; M: media; A: adventitia. Scale bar: $100 \mu$ m. (c) Total RNA was extracted from pooled thoracic aortas of 8-, 12-, 16-, and 24-week-old apoE-KO and B6 mice. MYPT1 mRNA was detected by RT-PCR using specific primers described in the Material and Methods. The upper panel shows a representative agarose gel; the lower panel summarizes densitometry results for total MYPT1, total PP1 $\delta$, and the percentage of LZ-positive/LZ-negative MYPT1 mRNA levels. The results were normalized with 8-week-old B6 mice and expressed as the mean \pm s.e.m. from three or four independent experiments. ${ }^{*} P<0.05,{ }^{* *} P<0.01$ compared with age-matched $\mathrm{B} 6$ mice.

sion in the aortas of apoE-KO mice. This result correlates well with decreased oxidative stress following estrogen treatment.

\section{MYPT1 Downregulation Contributes to Abnormal Contraction and Relaxation in the Aortic Rings of ApoE- KO mice}

Given that MYPT1 regulates MP activity, ${ }^{3}$ the effects of decreased MYPT1 expression on contraction and relaxation of aortic rings were examined. The aortic rings of 20-weekold apoE-KO mice and B6 mice were stimulated with the $\alpha_{1}$ adrenoceptor agonist phenylephrine and thromboxane $\mathrm{A}_{2}$ analog U46619. In response to phenylephrine $(0.3 \mu \mathrm{M}$, near $\mathrm{EC}_{50}$ ) stimulation, the aortic rings from apoE-KO mice developed greater isometric tension compared with those from B6 mice. No significant difference was observed following U46619 (30 nM, near $\mathrm{EC}_{50}$ ) stimulation, but 


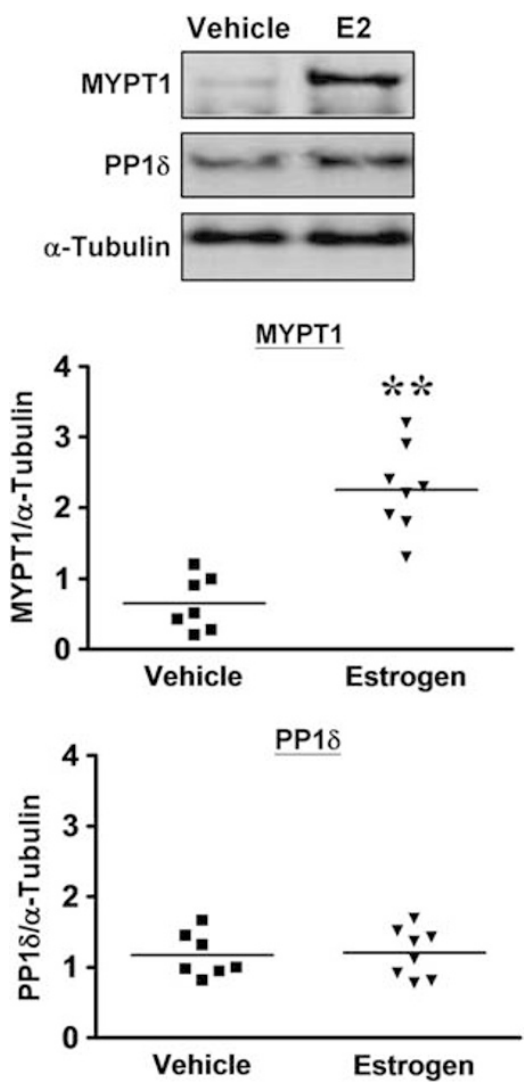

Figure 6 The effect of oral estrogen treatment on myosin phosphatase targeting subunit 1 (MYPT1) expression in apolipoprotein E-knockout (apoE-KO) mice. Female apoE-KO mice were ovariectomized at 11 weeks of age. One week later, the mice were fed an estrogen-free diet containing $0.15 \%$ cholesterol and orally administered $17 \beta$-estradiol (E2; $n=8)(6 \mu \mathrm{g} /$ day) or $5 \%$ ethanol (control vehicle, Ctrl; $n=7)$ for 12 weeks. The MYPT 1 and PP $1 \delta$ protein expression levels were examined by western blot analysis. The results were normalized with control vehicletreated mice and expressed as the mean \pm s.e.m. ${ }^{* * P}<0.01$ compared with the control group.

these aortic rings exhibited the trend to develop higher tension (Figure 7a). In contrast, maximal contractile tension toward both vasoconstrictors did not differ significantly between apoE-KO and B6 mice (data not shown). To examine relaxation, aortic rings were precontracted with phenylephrine or U46619, which was followed by treatment with cumulative concentrations $\left(10^{-8}-10^{-5} \mathrm{M}\right)$ of a $\mathrm{NO}$ donor, SNP. For both phenylephrine- and U46619-stimulated contraction, all SNP concentrations exhibited the trend to induce smaller effects on relaxation in the aortic rings of apoE-KO mice compared with B6 mice. Significant difference was detected with $10^{-6}$ and $10^{-5} \mathrm{M}$ SNP in U46619-precontracted aortic rings (Figure $7 \mathrm{~b}$ ).

\section{DISCUSSION}

This study provided the first evidence that knockdown of MYPT1 increased stress fiber formation and attenuated PDGF-stimulated cell migration in HASMCs. In addition, superoxide and peroxynitrite treatment both reduced MYPT1 protein levels in HASMCs. In vivo MYPT1 protein levels decreased during the course of atherosclerosis progression, which correlated with the increased contractile sensitivity, and was reversed by oral estrogen treatment in apoE-KO mice. In conjunction with our previous results that reducing oxidative stress contributes to oral estrogen-induced decreases in atherosclerotic lesions of apoE-KO mice, ${ }^{20}$ these findings indicate that the ROS-mediated decrease in MYPT1 is likely a mechanistic explanation for aberrant vascular contractility in atherosclerosis.

In the HeLa cells, MYPT1 knockdown increases MLC $_{20}$ phosphorylation and $\mathrm{F} / \mathrm{G}$ actin ratio, while it decreases serum-induced cell migration. ${ }^{27}$ Similarly, our results in HASMCs showed that the actin stress fibers were increased and PDGF-increased cell migration was attenuated following shRNA-mediated knockdown of MYPT1. These results suggest that the loss of MYPT1 expression decreases the MP activity, which causes the aberrant turnover of $\mathrm{MLC}_{20}$ phosphorylation and inhibits cell migration. However, the advanced atherosclerotic lesions are characterized by the migration of smooth muscle cells from the medial layer of the artery wall into the subendothelial space of the intima. ${ }^{16}$ Thus, given the function of MYPT1 in controlling cell migration, our results suggest that before MYPT1 expression is reduced, MYPT1 levels in vascular smooth muscle cells keep the normal turnover of $\mathrm{MLC}_{20}$ phosphorylation that allows them to maintain the vascular tone. At the earlier stages of atherosclerosis, due to the endothelial dysfunction, the increased vascular permeability and leukocyte infiltration provide various cytokines and growth factors that are present in atherosclerotic lesions access to the media where they can stimulate vascular smooth muscle cells and induce the changes from the quiescent contractile phenotype to the migratory synthetic phenotype. These changes in combination with the maintained levels of MYPT1 permit vascular smooth muscle cells to migrate to the intima. While, in the later stages of atherosclerosis, reduction of MYPT1 may act as a brake to inhibit further migration of smooth muscle cells. In healthy vessels with functional endothelium, the function of MYPT1 in vascular smooth muscle cells is likely restricted to regulation of vascular tone rather than cell migration. In addition, smooth muscle cell proliferation mediates the progression of atherosclerosis. ${ }^{16}$ Myosin II phosphorylation is critical for mitosis and cytokinesis. ${ }^{32}$ Thus, it is not surprising that modulation of MYPT1 alters cell proliferation. Interestingly, siRNA-mediated knockdown of MYPT1 in the HeLa cells inhibits anchorage-independent cell proliferation but does not modify the basal levels..$^{27,33}$ Whether MYPT1 downregulation affects cell proliferation in smooth muscle cells remains unknown and warrants future studies.

ROS has critical roles in the pathogenesis of atherosclerosis by regulating NO bioactivity, monocyte infiltration, mitogenesis, migration, and apoptosis of vascular cells. ${ }^{19}$ LY83583 

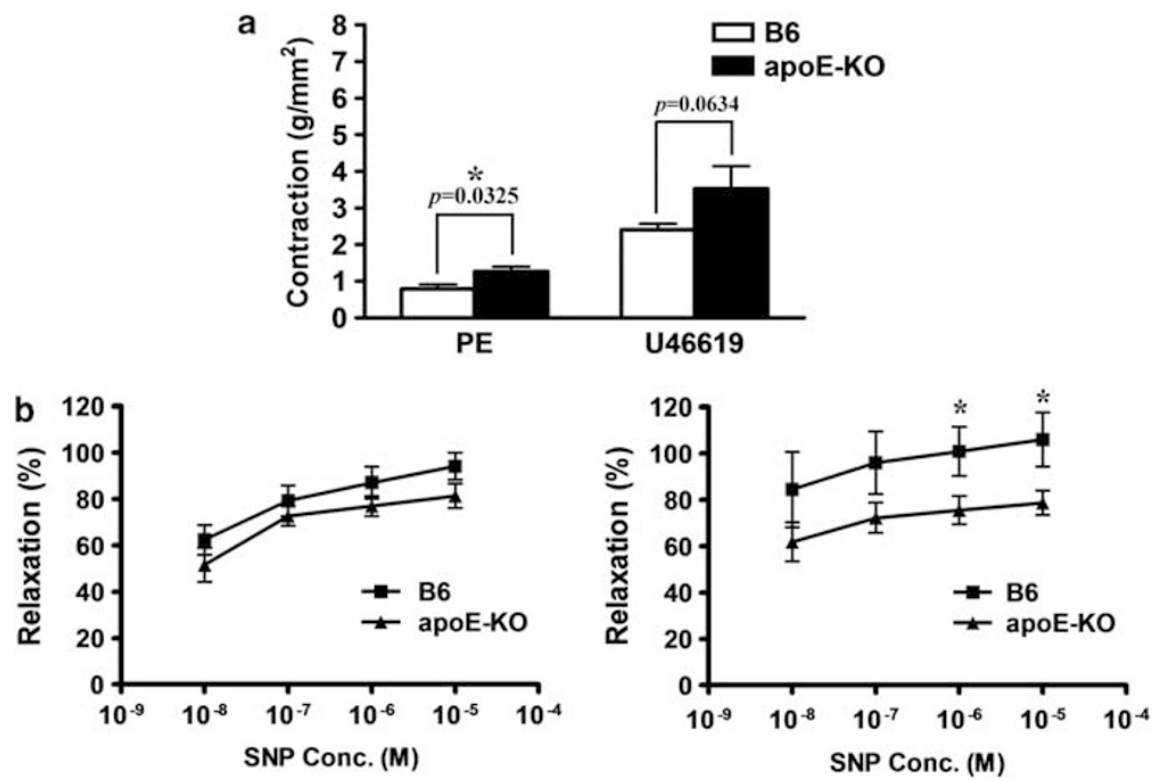

Figure 7 Contraction and relaxation of aortic rings in apolipoprotein E-knockout (apoE-KO) and B6 mice. (a) Isometric tension of aortic rings from 20-week-old apoE-KO and B6 mice contracted with $0.3 \mu \mathrm{M}$ phenylephrine or $30 \mathrm{nM}$ U46619. (b) Sodium nitroprusside (SNP) $\left(10^{-8}-10^{-5} \mathrm{M}\right)$-induced relaxation of aortic rings precontracted with $0.3 \mu \mathrm{M}$ phenylephrine (left panel) or $30 \mathrm{nM}$ U46619 (right panel). The results were expressed as the mean \pm s.e.m. from 13 (apoE-KO) or 8 (B6) independent experiments. ${ }^{*} P<0.05$ compared with $\mathrm{B} 6$ mice.

can generate superoxide production enzymatically and nonenzymatically. ${ }^{34}$ LY83583-induced superoxide production, but not $\mathrm{H}_{2} \mathrm{O}_{2}$, increases procollagen $\alpha 1$ (I) mRNA levels in canine aortic smooth muscle cells, which suggests that superoxide anion regulates gene expression. ${ }^{35}$ Our results that LY83583 treatment reduced both MYPT1 mRNA and protein levels in HASMCs are consistent with this notion. Furthermore, the attenuation of LY83583-reduced MYPT1 protein levels by the co-treatment with a membranepermeable SOD strongly implicates a role for superoxide anion in MYPT1 reduction. By contrast, $\mathrm{H}_{2} \mathrm{O}_{2}$ treatment did not alter MYPT1 mRNA and protein levels in HASMCs. These results support the notion that various ROS have differential roles in cellular functions. ${ }^{36}$ Superoxide anion reacts readily with $\mathrm{NO}$ to form peroxynitrite, which is a more powerful oxidant involved in various human diseases. ${ }^{21}$ Peroxynitrite is known to induce cell death in various cell types, such as apoptosis of epithelial cells, macrophages, neuronal cell line $\mathrm{PC12}$, and endothelial cells. ${ }^{21,37,38}$ Interestingly, peroxynitrite, in contrast to $\mathrm{H}_{2} \mathrm{O}_{2}$, did not induce apoptosis of smooth muscle cells to significant extent in the current study. Peroxynitrite interacts with amino acids, such as cysteine, methionine, and tyrosine, to produce nitrated proteins that undergo facilitated degradation by proteasome. ${ }^{39,40}$ In atherosclerosis, the ubiquitin-proteasome system is required for smooth muscle cell proliferation and survival in vitro along with neointimal formation in vivo. ${ }^{41}$ In rat mesenteric artery ligation model, low blood flow decreases MYPT1 expression, which is blocked by pretreating with a proteasome inhibitor, MG-132. ${ }^{42}$ In the present study, co-treatment of MG-132 eliminated peroxynitrite-induced downregulation of MYPT1 protein levels in HASMC. This finding provides another example for ubiquitin-proteasome system-mediated regulation of protein expression in cells under oxidative stress in aortic smooth muscle cells. In accordance with our previous results that oral estrogen treatment reduces ROS levels in apoE-KO mice by modulating the ROS-generating and -scavenging enzyme expression, ${ }^{20}$ results from this study showed that oral estrogen treatment upregulated MYPT1 protein levels in apoE-KO mice. These in vitro and in vivo findings combined clearly indicate that ROS acts as important mediators to regulate the MYPT1 expression during atherosclerosis progression. It is also noteworthy that ROS modulates $\alpha_{1^{-}}$ adrenoceptor-activated vascular smooth muscle contraction by altering the phosphorylation levels of MYPT1. ${ }^{43}$ Taken together, MYPT1 functions in smooth muscle cells are regulated by ROS under both physiological and pathological conditions.

It has been well characterized that phosphorylation of MYPT1 at Thr696 and Thr850 both inhibits MP activity. ${ }^{4,5}$ Phosphorylation at Thr696 inhibits the catalytic activity of MP whereas Thr850 phosphorylation reduces binding of MYPT1 to myosin. ${ }^{44}$ A recent study showed that treatment with LY83583 induces MYPT1 phosphorylation at Thr850 in rat small pulmonary arteries. ${ }^{45}$ In another study, treatment with $\mathrm{H}_{2} \mathrm{O}_{2}$ for $1 \mathrm{~h}$ enhances MYPT1 phosphorylation at both Thr696 and Thr850 in porcine pulmonary artery. ${ }^{46}$ Yet, whether peroxynitrite induces MYPT1 phosphorylation in vascular smooth muscle is unknown. In the present study, our results showed that peroxynitrite treatment induced MYPT1 phosphorylation at both Thr696 and Thr850 in 
HASMC. Interestingly, treatment with LY83583 or $\mathrm{H}_{2} \mathrm{O}_{2}$ did not affect the levels of MYPT1 phosphorylation at either Thr696 or Thr850. Taken together, these results suggested that LY83583 and $\mathrm{H}_{2} \mathrm{O}_{2}$ may have different effects on smooth muscle cells in arteries of different sizes.

Modulation of MYPT1 abundance and differential expression of spliced variants occurs during development, as well as under physiological and pathological conditions. ${ }^{9}, 12,14,15,47,48$ In rat uterus, MYPT1 mRNA levels are decreased during the later stages of pregnancy. ${ }^{15}$ Hypoxia exposure increases MYPT1 protein levels in the rat aorta. ${ }^{14}$ Interestingly, ligation-induced portal hypertension is associated with MYPT1 downregulation and switching from the LZ-negative to LZ-positive isoform in portal vein and the upstream mesenteric artery. ${ }^{47}$ In coronary artery ligation-induced congestive heart failure, resistance to NO-mediated relaxation is attributed to the decreased expression of the LZ-positive MYPT1 isoform. ${ }^{12}$ In the present study, we did not detect any change either in the overall MYPT1 mRNA expression or in the relative abundance of LZ-positive MYPT1 isoform in apoE-KO mice during atherosclerosis progression. Instead, a reduction in MYPT1 may result from increased protein degradation, which adds a new dimension to the regulation of MYPT1 expression at the level of protein stability. Collectively, these results suggest that altering MYPT1 expression, which localizes phosphatase activity to myosin and triggers $\mathrm{MLC}_{20}$ dephosphorylation, in smooth muscle cells might have a mechanistic role in modulating smooth muscle function under physiological and pathological conditions. In the present study, at $\mathrm{EC}_{50}$ concentration, the aortic rings developed more tension in apoE-KO mice than $\mathrm{B} 6$ mice in response to phenylephrine stimulation and exhibited a similar tendency toward U46619 stimulation. In contrast, the maximal tension induced by either vasoconstrictor did not vary significantly between two groups. These results clearly indicate that decreased MYPT1 protein levels may lead to increased sensitivity toward vasoconstrictors. Under more severe atherosclerosis, decreased MYPT1 may act in concert with factors that inhibit MP activity via MYPT1 phosphorylation to cause hypercontractility. ${ }^{17,49}$ Smaller SNP-induced relaxation in the aortic rings of apoE-KO mice suggests that reducing MYPT1 expression decreases MP activity and contributes to diminished relaxation. The mechanisms underlying the differential relaxational effects of SNP on phenylephrine- and U46619-precontracted aortic rings remain to be determined.

In summary, our results strongly suggested that downregulation of MYPT1 in aortic smooth muscle cells is mediated by oxidative stress during atherosclerosis progression. The decrease in MYPT1 levels reduces vascular smooth muscle cell migration activity and contributes to the aberrant contractility of atherosclerotic vessels.

Supplementary Information accompanies the paper on the Laboratory Investigation website (http://www.laboratoryinvestigation.org)

\section{ACKNOWLEDGEMENTS}

We thank Ms Ya-Fen Wu for the excellent technical assistance in contraction measurements. This study was supported by the MOE Program for Promoting Academic Excellence of Universities 91-B-FA09-2-4 and the National Science Council Grants NSC95-2752-B-006-003-PAE, NSC98-2320B-006-025-MY3 of Taiwan.

\section{DISCLOSURE/CONFLICT OF INTEREST}

The authors declare no conflict of interest.

1. Horowitz A, Menice CB, Laporte R, et al. Mechanisms of smooth muscle contraction. Physiol Rev 1996;76:967-1003.

2. Somlyo AP, Somlyo AV. Ca2 + sensitivity of smooth muscle and nonmuscle myosin II: modulated by G proteins, kinases, and myosin phosphatase. Physiol Rev 2003;83:1325-1358.

3. Ito $M$, Nakano $T$, Erdodi $F$, et al. Myosin phosphatase: structure, regulation and function. Mol Cell Biochem 2004;259:197-209.

4. Kimura K, Ito M, Amano M, et al. Regulation of myosin phosphatase by Rho and Rho-associated kinase (Rho-kinase). Science 1996;273: 245-248.

5. lizuka K, Yoshii A, Samizo K, et al. A major role for the rho-associated coiled coil forming protein kinase in G-protein-mediated $\mathrm{Ca} 2+$ sensitization through inhibition of myosin phosphatase in rabbit trachea. Br J Pharmacol 1999;128:925-933.

6. Lee MR, Li L, Kitazawa T. Cyclic GMP causes $\mathrm{Ca} 2+$ desensitization in vascular smooth muscle by activating the myosin light chain phosphatase. J Biol Chem 1997;272:5063-5068.

7. Wu X, Somlyo AV, Somlyo AP. Cyclic GMP-dependent stimulation reverses G-protein-coupled inhibition of smooth muscle myosin light chain phosphate. Biochem Biophys Res Commun 1996;220: 658-663.

8. Hartshorne DJ, Ito M, Erdodi F. Myosin light chain phosphatase: subunit composition, interactions and regulation. J Muscle Res Cell Motil 1998;19:325-341.

9. Khatri JJ, Joyce KM, Brozovich FV, et al. Role of myosin phosphatase isoforms in CGMP-mediated smooth muscle relaxation. J Biol Chem 2001;276:37250-37257.

10. Huang QQ, Fisher SA, Brozovich FV. Unzipping the role of myosin light chain phosphatase in smooth muscle cell relaxation. J Biol Chem 2004;279:597-603.

11. Surks HK, Mochizuki N, Kasai $\mathrm{Y}$, et al. Regulation of myosin phosphatase by a specific interaction with cGMP-dependent protein kinase lalpha. Science 1999;286:1583-1587.

12. Karim $\mathrm{SM}$, Rhee $\mathrm{AY}$, Given $\mathrm{AM}$, et al. Vascular reactivity in heart failure: role of myosin light chain phosphatase. Circ Res 2004;95:612-618.

13. Hartshorne DJ, Ito M, Erdodi F. Role of protein phosphatase type 1 in contractile functions: myosin phosphatase. J Biol Chem 2004:279:37211-37214.

14. Teoh $\mathrm{H}$, Zacour $M$, Wener $A D$, et al. Increased myofibrillar protein phosphatase- 1 activity impairs rat aortic smooth muscle activation after hypoxia. Am J Physiol Heart Circ Physiol 2003;284:H1182-H1189.

15. Trujillo M, Candenas L, Cintado CG, et al. Hormonal regulation of the contractile response induced by okadaic acid in the rat uterus. J Pharmacol Exp Ther 2001;296:841-848.

16. Ross R. Atherosclerosis-an inflammatory disease. N Engl J Med 1999;340:115-126.

17. Shimokawa $\mathrm{H}$, Tomoike $\mathrm{H}$, Nabeyama $\mathrm{S}$, et al. Coronary artery spasm induced in atherosclerotic miniature swine. Science 1983;221: 560-562.

18. Madamanchi NR, Vendrov A, Runge MS. Oxidative stress and vascular disease. Arterioscler Thromb Vasc Biol 2005;25:29-38.

19. Lassegue B, Griendling KK. NADPH oxidases: functions and pathologies in the vasculature. Arterioscler Thromb Vasc Biol 2010;30:653-661.

20. Wing LY, Chen YC, Shih YY, et al. Effects of oral estrogen on aortic ROSgenerating and -scavenging enzymes and atherosclerosis in apoEdeficient mice. Exp Biol Med (Maywood) 2009;234:1037-1046.

21. Pacher P, Beckman JS, Liaudet L. Nitric oxide and peroxynitrite in health and disease. Physiol Rev 2007;87:315-424.

22. Wattanapitayakul SK, Weinstein DM, Holycross BJ, et al. Endothelial dysfunction and peroxynitrite formation are early events in 
angiotensin-induced cardiovascular disorders. Faseb J 2000;14 271-278.

23. Kastle M, Grune T. Protein oxidative modification in the aging organism and the role of the ubiquitin proteasomal system. Curr Pharm Des 2011;17:4007-4022.

24. Stadtman ER. Protein oxidation and aging. Free Radic Res 2006;40:1250-1258.

25. Oustwani CS, Tsihlis ND, Vavra AK, et al. Nitric oxide increases lysine 48-linked ubiquitination following arterial injury. J Surg Res 2011 170:e169-e177.

26. Tsihlis ND, Oustwani CS, Vavra AK, et al. Nitric oxide inhibits vascular smooth muscle cell proliferation and neointimal hyperplasia by increasing the ubiquitination and degradation of UbcH10. Cell Biochem Biophys 2011;60:89-97.

27. Xia D, Stull JT, Kamm KE. Myosin phosphatase targeting subunit 1 affects cell migration by regulating myosin phosphorylation and actin assembly. Exp Cell Res 2005;304:506-517.

28. Neppl RL, Lubomirov LT, Momotani $\mathrm{K}$, et al. Thromboxane A2-induced bi-directional regulation of cerebral arterial tone. J Biol Chem 2009;284:6348-6360.

29. Lontay B, Kiss A, Gergely P, et al. Okadaic acid induces phosphorylation and translocation of myosin phosphatase target subunit 1 influencing myosin phosphorylation, stress fiber assembly and cell migration in HepG2 cells. Cell Signal 2005;17:1265-1275.

30. Lo IC, Shih JM, Jiang MJ. Reactive oxygen species and ERK 1/2 mediate monocyte chemotactic protein-1-stimulated smooth muscle cell migration. J Biomed Sci 2005;12:377-388.

31. Baas AS, Berk BC. Differential activation of mitogen-activated protein kinases by $\mathrm{H} 2 \mathrm{O} 2$ and $\mathrm{O} 2-$ in vascular smooth muscle cells. Circ Res 1995;77:29-36.

32. Komatsu S, Yano $T$, Shibata $M$, et al. Effects of the regulatory light chain phosphorylation of myosin II on mitosis and cytokinesis of mammalian cells. J Biol Chem 2000;275:34512-34520.

33. Umeda D, Yamada K, Tachibana H. H89 (N-[2-(p-bromocinnamylamino) ethyl]-5-isoquinolinesulfonamide) induces reduction of myosin regulatory light chain phosphorylation and inhibits cell proliferation. Eur J Pharmacol 2008;590:61-66.

34. Hasegawa T, Bando A, Tsuchiya K, et al. Enzymatic and nonenzymatic formation of reactive oxygen species from 6-anilino-5,8quinolinequinone. Biochim Biophys Acta 2004;1670:19-27.
35. Absood A, Furutani A, Kawamura T, et al. A comparison of oxidized LDL-induced collagen secretion by graft and aortic SMCs: role of PDGF. Am J Physiol Heart Circ Physiol 2004;287:H1200-H1206.

36. Taniyama Y, Griendling KK. Reactive oxygen species in the vasculature: molecular and cellular mechanisms. Hypertension 2003;42:1075-1081.

37. Sandoval M, Zhang XJ, Liu X, et al. Peroxynitrite-induced apoptosis in T84 and RAW 264.7 cells: attenuation by L-ascorbic acid. Free Radic Biol Med 1997;22:489-495.

38. Shacka JJ, Sahawneh MA, Gonzalez JD, et al. Two distinct signaling pathways regulate peroxynitrite-induced apoptosis in PC12 cells. Cell Death Differ 2006;13:1506-1514.

39. Alvarez B, Radi R. Peroxynitrite reactivity with amino acids and proteins. Amino Acids 2003;25:295-311.

40. Souza JM, Choi I, Chen Q, et al. Proteolytic degradation of tyrosine nitrated proteins. Arch Biochem Biophys 2000;380:360-366.

41. Meiners S, Laule M, Rother W, et al. Ubiquitin-proteasome pathway as a new target for the prevention of restenosis. Circulation 2002;105:483-489.

42. Zhang $\mathrm{H}$, Fisher SA. Conditioning effect of blood flow on resistance artery smooth muscle myosin phosphatase. Circ Res 2007;100:730-737.

43. Tsai $\mathbf{M H}$, Jiang MJ. Reactive oxygen species are involved in regulating alpha1-adrenoceptor-activated vascular smooth muscle contraction. J Biomed Sci 2010;17:67.

44. Lincoln TM. Myosin phosphatase regulatory pathways: different functions or redundant functions? Circ Res 2007;100:10-12.

45. Knock GA, Snetkov VA, Shaifta Y, et al. Superoxide constricts rat pulmonary arteries via Rho-kinase-mediated $\mathrm{Ca}(2+)$ sensitization. Free Radic Biol Med 2009;46:633-642.

46. Maki J, Hirano M, Hoka S, et al. Involvement of reactive oxygen species in thrombin-induced pulmonary vasoconstriction. Am J Respir Crit Care Med 2010;182:1435-1444.

47. Payne MC, Zhang HY, Shirasawa Y, et al. Dynamic changes in expression of myosin phosphatase in a model of portal hypertension Am J Physiol Heart Circ Physiol 2004;286:H1801-H1810.

48. Payne MC, Zhang HY, Prosdocimo T, et al. Myosin phosphatase isoform switching in vascular smooth muscle development. J Mol Cell Cardiol 2006;40:274-282.

49. Kandabashi T, Shimokawa H, Mukai $Y$, et al. Involvement of rho-kinase in agonists-induced contractions of arteriosclerotic human arteries. Arterioscler Thromb Vasc Biol 2002;22:243-248. 